Article

\title{
Weld Seam Geometry and Electrical Resistance of Laser-Welded, Aluminum-Copper Dissimilar Joints Produced with Spatial Beam Oscillation
}

\author{
Michael Jarwitz *, Florian Fetzer, Rudolf Weber and Thomas Graf \\ Institut fuer Strahlwerkzeuge (IFSW), Pfaffenwaldring 43, 70569 Stuttgart, Germany; \\ florian.fetzer@ifsw.uni-stuttgart.de (F.F.); rudolf.weber@ifsw.uni-stuttgart.de (R.W.); \\ thomas.graf@ifsw.uni-stuttgart.de (T.G.) \\ * Correspondence: michael.jarwitz@ifsw.uni-stuttgart.de; Tel.: +49-711-685-60209
}

Received: 8 June 2018; Accepted: 28 June 2018; Published: 3 July 2018

\begin{abstract}
Spatial beam oscillation during laser beam welding of aluminum to copper was investigated. The beam was spatially oscillated perpendicular to the direction of feed in a sinusoidal mode. The influence of the oscillation amplitude and frequency on the weld seam geometry and the implications on the electrical resistance of the joints was investigated. It was found that spatial beam oscillation allows to set the welding depth and seam width virtually independent of each other. Furthermore, low welding depths into the lower copper sheet in combination with high ratios of seam width at the interface of the two sheets to welding depth into the lower copper sheet result in low electrical resistances of the welds. Low electrical resistances were found to correlate with high mechanical strengths of the welds.
\end{abstract}

Keywords: laser beam welding; spatial beam oscillation; dissimilar metals; aluminum; copper

\section{Introduction}

Joining of aluminum $(\mathrm{Al})$ to copper $(\mathrm{Cu})$ is required for high-power, light-weight electrical applications, such as e-mobility or battery applications [1,2]. However, welding of the metal combination $\mathrm{Al}$ and $\mathrm{Cu}$ is challenging due to the formation of intermetallic phases in the weld seam [3] and the strongly differing thermophysical properties of the two materials, such as the melting temperature and the heat conductivity. The intermetallic phases have a higher brittleness, lower mechanical strength, and higher electrical resistivity than the base materials [4], which deteriorates both the mechanical and electrical properties of the weld joint. Therefore, the formation of these intermetallic phases during the welding process must be minimized. Reliable joining of $\mathrm{Al}$ to $\mathrm{Cu}$ with high quality by means of an unmodulated continuous wave $(\mathrm{cw})$ laser welding process has proven to be challenging. When welding with a cw laser, significant mixing of the two materials and large cracks in the weld seam are a major problem [3]. A strong mixture of the materials and the formation of intermetallic phases in the weld seam is common [5]. The use of a spatial oscillation of the laser beam has proven to be a suitable measure to stabilize the welding process, especially the welding depth. The stabilization of the welding depth at low-penetration depths for laser welding of aluminum close to the deep penetration threshold is possible [6]. Furthermore, a stabilization of the welding depth against focal shift by the use of spatial beam oscillation has been observed [7]. Spatial oscillation of the laser beam has also been applied successfully for welding of $\mathrm{Al}$ to $\mathrm{Cu}$ to improve the weld quality. Homogeneous mixing of the two materials in the weld seam was demonstrated using a single-mode fiber laser and spatial beam oscillation [8]. Smaller mixing zones and less pores and cracks in the welds (compared to rectilinear welding) can be obtained using a pulsed laser and spatial beam oscillation [9]. Large joining widths at the interface and low penetration depths into the lower Cu sheet 
were generated by welding with a fiber laser and spatial beam oscillation [3]. The resulting welds showed a higher tensile strength than welds produced without a spatial oscillation of the laser beam. The electrical resistance of the joints is reported to decrease with an increase in the joining area. Small thicknesses $(<5 \mu \mathrm{m})$ of the intermetallic phase layer at the interface could be achieved by the combination of temporal power modulation and spatial beam oscillation [5]. High shear strengths of the joints were obtained due to these small thicknesses of the intermetallic phase layer. In Ref. [10], it was also shown that the shear strength was reduced drastically if the thickness of the intermetallic phase layer was smaller than $3 \mu \mathrm{m}$. In addition, a low thickness of the intermetallic phase layer also results in a low electrical resistance of the joint, and there is a correlation between high mechanical strength and the low electrical resistance of the joints. Most of these investigations focused on welding with small focal diameters (about $50 \mu \mathrm{m}$ or less) and comparably low laser powers $(<1 \mathrm{~kW})$. In contrast to the findings summarized in this section, the investigations presented in this paper focus on reproducible joining of aluminum to copper using multi-mode lasers with high power in combination with spatial beam oscillation. The weld seam geometry is known to be influenced by the spatial beam oscillation [11]. In the present paper, the influence of the oscillation parameters on the weld seam geometry was investigated. The focus was to quantify the relation between the geometry and the resultant electrical and mechanical properties of the welds.

We state that the resultant electrical resistance of the joints is mainly influenced by three factors:

(1) the seam width at the interface between the sheets,

(2) the metallurgical composition of the weld seam,

(3) the constancy of the geometrical properties of the weld seam along the welding direction,

and that spatial oscillation of the laser beam is a suitable measure to optimize these three factors. Therefore, the influence of the oscillation parameters on the geometry of the weld seam and the mixing of the two joining partners are investigated. The dependence of the electrical resistance on the geometry of the weld seam is evaluated, as well as the correlation between the electrical resistance and the mechanical strength of the connections.

\section{Materials and Methods}

\subsection{Experimental Setup}

Remote laser welding of pure aluminum (A199.5) to pure copper (Cu-OF) in overlap configuration was investigated. A sketch of the geometry of the specimens which were used for the welding trials and the subsequent shear tests is shown in Figure 1. The thickness of each sheet was $1 \mathrm{~mm}$ and Al was positioned on top. Linear weld seams with a length of $35 \mathrm{~mm}$ were produced. Measurements of the electrical resistance (four-point measurement, detailed description in Section 2.2) and tensile shear tests (based on DIN EN ISO 14273) of the generated weld seams were performed on these samples.

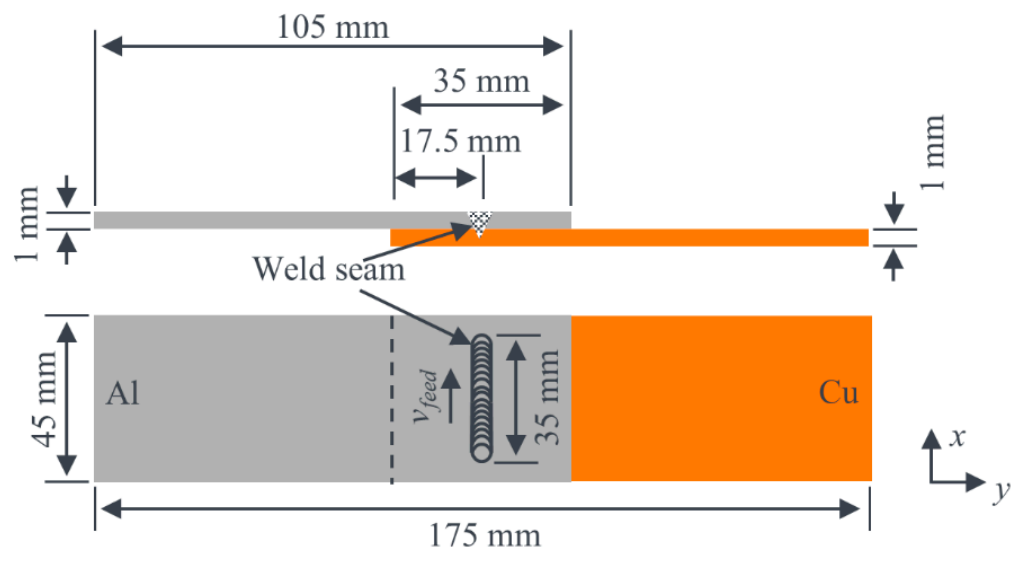

Figure 1. Sketch of the geometry of the specimens used for the welding trials and shear tests. 
The used laser source was a Laserline LDF 4000.8 (Laserline GmbH, Mühlheim-Kärlich, Germany) solid-state laser with a wavelength of $1.08 \mu \mathrm{m}$ whose beam was coupled to a transport fiber with a core diameter of $100 \mu \mathrm{m}$. The processing beam was focused on the top surface of the $\mathrm{Al}$ sheet using a Scansonic RLW-A remote welding optics (Scansonic MI GmbH, Berlin, Germany), which was inclined by an angle of $10^{\circ}$ in direction of feed. The resulting focal diameter was $280 \mu \mathrm{m}$ and the Rayleigh-length of the processing beam was $5 \mathrm{~mm}$.

In a first step, rectilinear welds were performed at a feed rate of $v_{\text {feed }}=6 \mathrm{~m} / \mathrm{min}$ and varying laser powers from $1.5 \mathrm{~kW}$ up to $3.25 \mathrm{~kW}$. Subsequently, spatial beam oscillation perpendicular to the feed direction was applied with a trajectory corresponding to

$$
\left(\begin{array}{c}
x(t) \\
y(t)
\end{array}\right)=\left(\begin{array}{c}
v_{\text {feed }} \cdot t \\
A_{y} \cdot \sin \left(2 \pi f_{y} \cdot t\right)
\end{array}\right)
$$

The oscillation frequency $f_{y}$ was varied from $200 \mathrm{~Hz}$ to $1000 \mathrm{~Hz}$ and the oscillation amplitude $A_{y}$ was varied from $0.25 \mathrm{~mm}$ up to $1 \mathrm{~mm}$. The feed rate $v_{\text {feed }}=6 \mathrm{~m} / \mathrm{min}$ was constant throughout all experiments and a constant laser power of $P=3.25 \mathrm{~kW}$ was used for the experiments with spatial beam oscillation. No shielding gas was used in the experiments.

\subsection{Evaluation Procedure and Basic Considerations}

The geometrical properties and the electrical resistances of the welds were measured to evaluate the experiments. Figure 2 shows optical microscopy (a) and SEM (b) images of typical cross-sections of rectilinear welds. The measured geometrical properties of the welds were the welding depth $d$ into copper, the seam width $w$ at the interface, and the fused areas $A_{\mathrm{Al}}$ and $A_{\mathrm{Cu}}$ of aluminum and copper, respectively. These quantities are indicated in the sketch of the cross-section shown in Figure 2c. From the SEM image (Figure 2b), it can be seen that there is an inhomogeneous distribution of the copper throughout the entire cross-section of the weld seam in the case of the rectilinear welding, even for low welding depths into the lower copper sheet. The averaged $\mathrm{Cu}$ content $X_{\mathrm{Cu}, \mathrm{avg}}=A_{\mathrm{Cu}} \cdot \rho_{\mathrm{Cu}} /\left(A_{\mathrm{Cu}} \cdot \rho_{\mathrm{Cu}}+A_{\mathrm{Al}} \cdot \rho_{\mathrm{Al}}\right)$ in the weld seam was used to quantify the mixing ratio of the two metals, and it was calculated from the fused areas of aluminum and copper weighted by their densities. The fused areas were measured from the cross-sections, according to Figure 2c.

a)

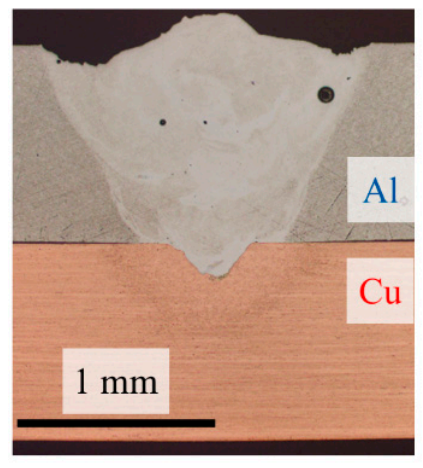

b)

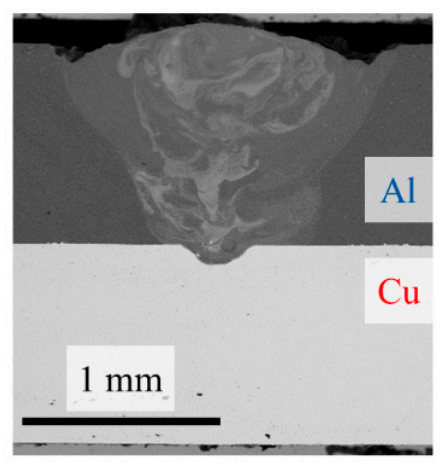

c)

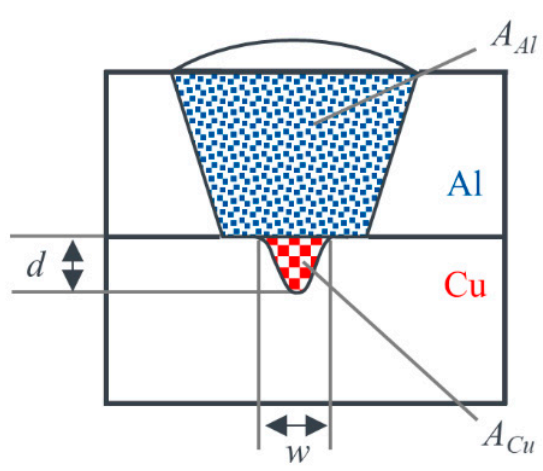

Figure 2. Images of typical cross-sections of welds produced by unmodulated rectilinear welding, optical microscopy (a) and SEM imaging (b); parameters: $P=2 \mathrm{~kW} ; v_{\text {feed }}=6 \mathrm{~m} / \mathrm{min} ; \lambda_{\text {laser }}=1.08 \mu \mathrm{m}$; $d_{\mathrm{f}}=280 \mu \mathrm{m} ; z_{\mathrm{f}}=0 \mathrm{~mm}, z_{\mathrm{R}}=5 \mathrm{~mm}$; (c) sketch of a typical cross-section with indication of the analyzed geometrical quantities: welding depth $d$ into $\mathrm{Cu}$, seam width $w$ at interface, and fused areas $A_{\mathrm{Al}}$ and $A_{\mathrm{Cu}}$ of aluminum and copper, respectively. 
A four-point measurement setup was used to measure the electrical resistance of the joints. Figure $3 a$ shows a sketch of this setup and Figure $3 b$ shows the equivalent circuit for the measured electrical resistance $R_{\text {measure }}$.

a)

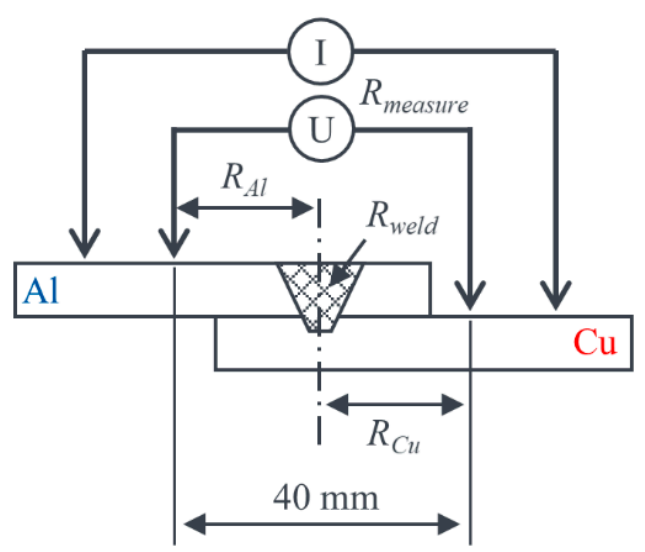

b)

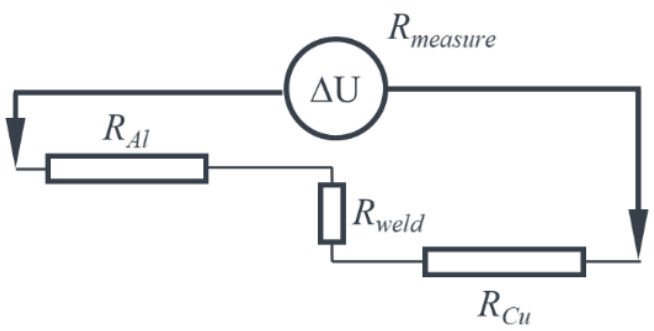

Figure 3. (a) Sketch of the four-point measurement setup used to determine the electrical resistance of the joints; (b) equivalent circuit for the measured resistance.

The measured electrical resistance $R_{\text {measure }}=R_{\mathrm{Al}}+R_{\text {weld }}+R_{\mathrm{Cu}}$ was considered idealized as the sum of the resistances $R_{\mathrm{Al}}$ and $R_{\mathrm{Cu}}$ of the two sheets up to the joint and the resistance of the weld seam itself $R_{\text {weld }}$. It is assumed that the resistances in the two base materials remain unaffected by the welding process, and therefore only the resistance of the weld seam is of interest. In a calibration measurement, the contribution of $R_{\mathrm{Al}}+R_{\mathrm{Cu}}$ to the measured resistance $R_{\text {measure }}$ was determined to be $21 \mu \Omega$, considering the contribution of the base sheets between the measurement tip and the center of the weld seam to the overall electrical resistance. The offset of $21 \mu \Omega$ was subtracted from each measured electrical resistance to obtain the electrical resistance of the weld seam $R_{\text {weld }}$. Current could further be conducted through the contact area between the two sheets, which can be considered as a parallel-connection to the weld. The electrical resistance of two sheets, which were not welded, but pressed together was measured to range between $10 \mathrm{~m} \Omega$ and $50 \mathrm{~m} \Omega$, which is about three orders of magnitude higher as the resistance of the welded parts. The contact area between the two sheets would influence the values of $R_{\text {measure }}$ by up to $2 \%$ and is therefore neglected.

Figure 4 shows a sketch of a cross-section of a weld seam with indication of the path of the electrical current. The relevant cross-sectional area is considered to be the cross-sectional area at the interface between the two sheets $\left(w \cdot l_{\text {weld }}\right)$ since the electrical current has to be conducted from one sheet of material to the other. With these assumptions we derive

$$
R_{\text {weld }} \propto \rho_{\mathrm{el}} \cdot \frac{s}{w \cdot l_{\text {weld }}}
$$

for the electrical resistance of the weld seam, where $\rho_{\mathrm{el}}$ is the electrical resistivity, $w$ the seam width at the interface, $l_{\text {weld }}$ the length of the weld seam, and $s$ the length of the path of the electrical current through the weld seam. It should be noted that Equation (2) was derived for a rectangular-shaped weld seam, and that for a more complex geometry, the consideration of the integral across the weld seam would be better suited. Nevertheless, from Equation (2) some basic requirements can be concluded to lead to a low $R_{\text {weld }}$. On the one hand, the cross-sectional area at the interface has to be large. This means a large $w$, since the length $l_{\text {weld }}$ of the weld seam is given by constructional boundary conditions in most cases. On the other hand, the electrical resistivity $\rho_{\mathrm{el}}$ of the weld seam has to be low. It is determined by the metallurgical composition of the weld seam. Since the electrical resistivity $\rho_{\mathrm{el}}$ of the intermetallic phases is much higher than that of the base materials [4], the amount of intermetallic phases in the weld seam should be as low as possible. Due to the strong convection in the weld pool 
during deep penetration laser welding, the liquid joining partners are mixed. This mixture of both materials in the liquid phase favors the formation of intermetallic phases. The averaged $\mathrm{Cu}$ content in the weld seam is taken as a possible measure of the amount of mixed materials, but is not sufficient to determine the amount and local distribution of the intermetallic phases. With increasing welding depth into $\mathrm{Cu}$, the amount of fused $\mathrm{Cu}$ is expected to increase and with this the averaged $\mathrm{Cu}$ content. Therefore, the welding depth into $\mathrm{Cu}$ should be low to achieve a low $\rho_{\mathrm{el}}$ in the weld seam. This means that a high ratio of the seam width at the interface to the welding depth into $\mathrm{Cu}(w / d)$ is favorable to obtain a low $R_{\text {weld }}$. Moreover, the seam width and welding depth should be constant over the entire length of the weld seam.

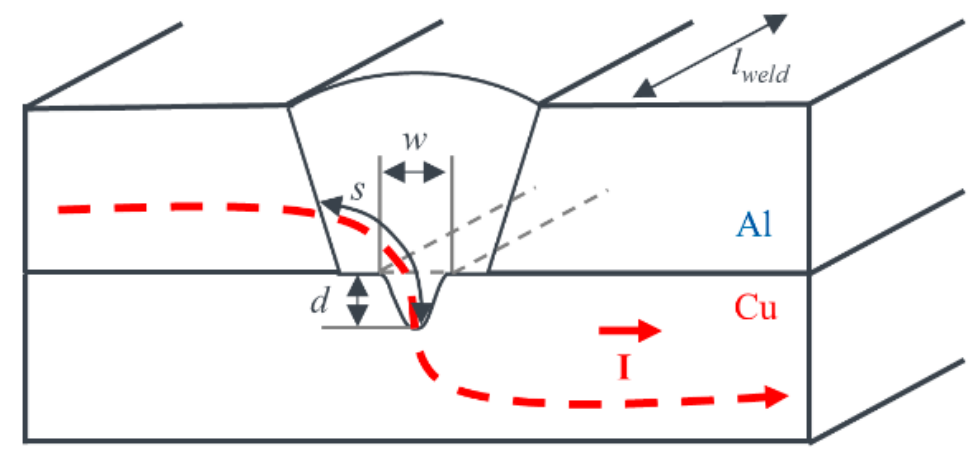

Figure 4. Sketch of a cross-section of the weld seam with indication of the path of an electrical current.

\section{Results}

\subsection{Welding Without Spatial Oscillation of the Laser Beam}

Figure 5 shows images of micrographs of cross-sections from welds produced with conventional rectilinear welding at different laser powers $P$.

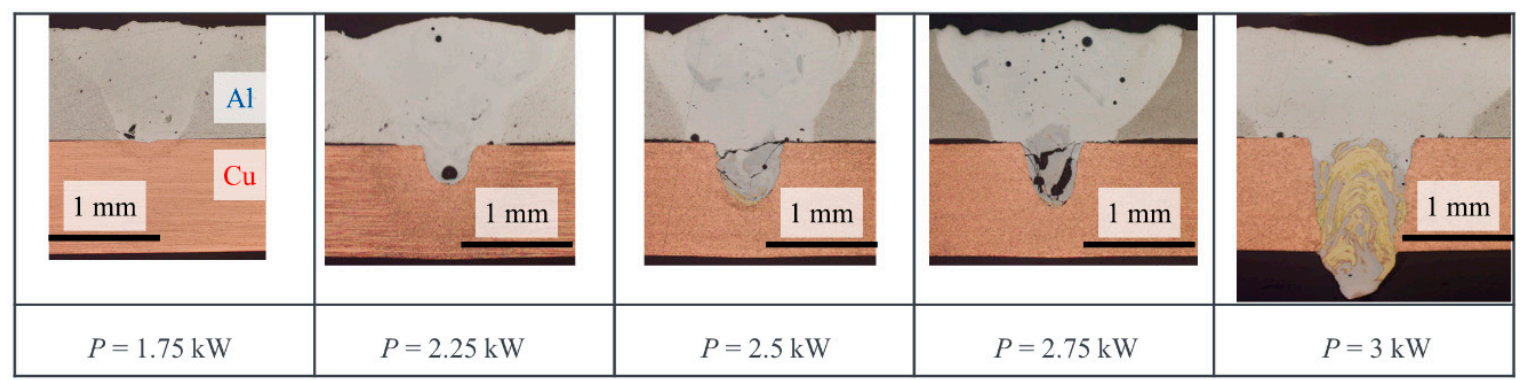

Figure 5. Micrographs of cross-sections of welds produced with conventional rectilinear welding, $v_{\text {feed }}=6 \mathrm{~m} / \mathrm{min}$.

As expected, the welding depth $d$ into the $\mathrm{Cu}$ sheet increases with increasing laser power. Also, the fused area of $\mathrm{Cu}$ as well as the mixing of both materials increases (indicated by the dark grayish and golden colored areas in the cross-sections). Moreover, pores and cracks can be found in the weld seams. The cracks are located in the lower part of the weld ( $\mathrm{Cu}$ side) and at the interface between the two sheets. Cracks are found in welds with a welding depth into the copper sheet of more than $0.5 \mathrm{~mm}$ and partial penetration of the $\mathrm{Cu}$ sheet. For small $d$ or full penetration of the $\mathrm{Cu}$ sheet, no cracks were observed.

Unmodulated, rectilinear laser welding of the two metals aluminum and copper itself is a highly instable process and prone to the formation of weld defects and fluctuations of the penetration depth [12-14]. This is also true for laser welding of the combination of the two metals as can be seen from Figure 6, which shows micrographs of cross-sections of the same weld seam at two different 
positions. It can be seen that $d$ and $w$ are not constant along the seam produced by rectilinear welding, and therefore point 3 of the above stated quality factors is not fulfilled.

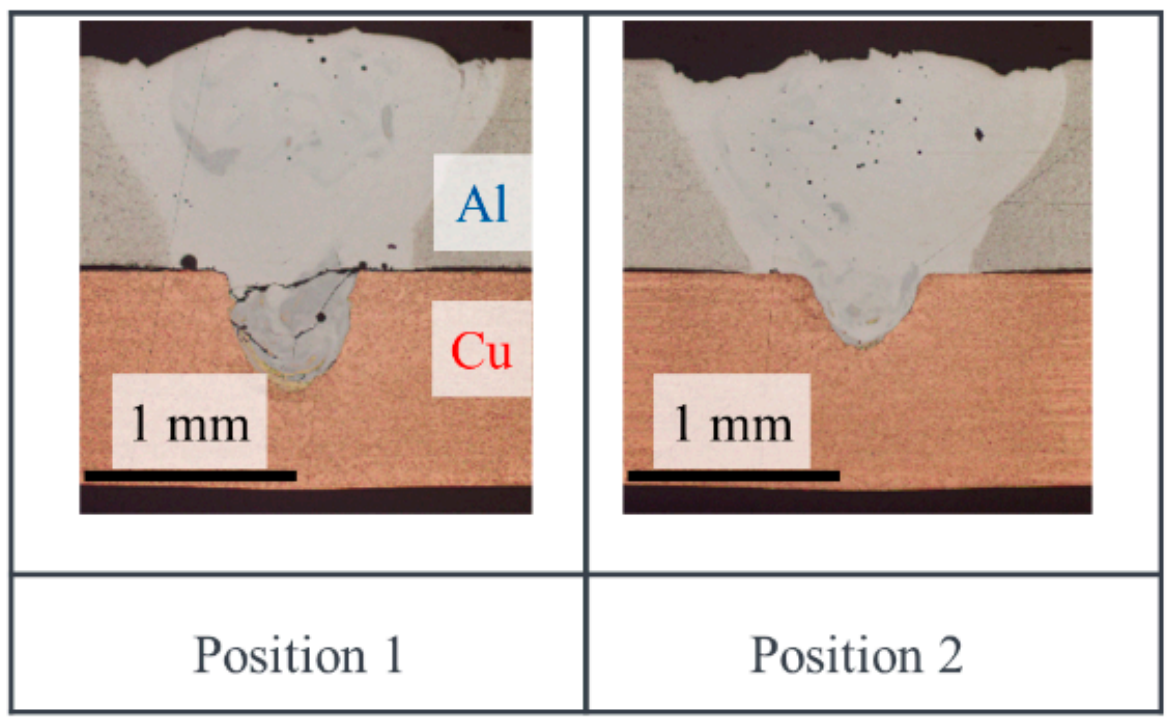

Figure 6. Micrographs of cross-sections at two positions along the same weld seam. $P=2.5 \mathrm{~kW}$; $v_{\text {feed }}=6 \mathrm{~m} / \mathrm{min}$.

The dependence of the weld seam geometry on the laser power is shown in Figure 7. Both the width and the depth of the weld seams increase with increasing laser power. The welding depth shows an almost linear increase with increasing laser power until full penetration of the $\mathrm{Cu}$ sheet is reached at $3 \mathrm{~kW}$. In contrast, the seam width shows a strong increase with laser power from $1.5 \mathrm{~kW}$ up to about $2.25 \mathrm{~kW}$, and then is seen to converge towards an upper limit. The averaged $\mathrm{Cu}$ content increases in close accordance with increasing welding depth.

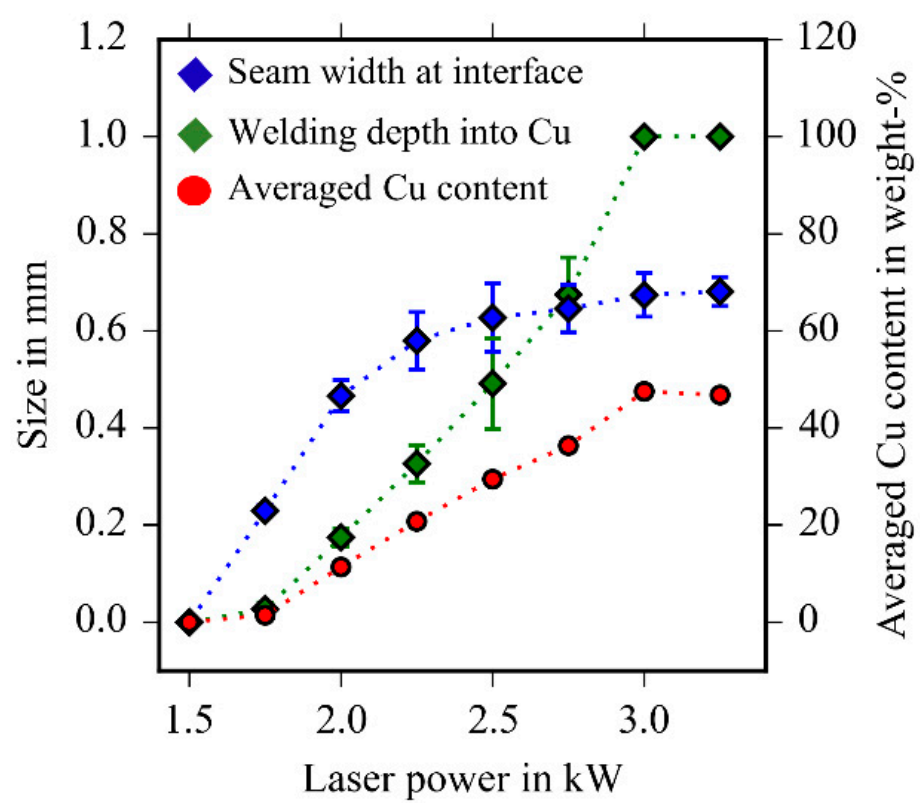

Figure 7. Seam width $w$ at the interface (blue), welding depth $d$ into $\mathrm{Cu}$ (green), and averaged $\mathrm{Cu}$ content (red) as a function of the laser power for welds produced with rectilinear welding at a feed rate of $6 \mathrm{~m} / \mathrm{min}$. 


\subsection{Welding with Spatial Oscillation of the Laser Beam}

Figure 8 shows optical micrographs of cross-sections from welds produced with spatial oscillation of the laser beam for different oscillation parameters.

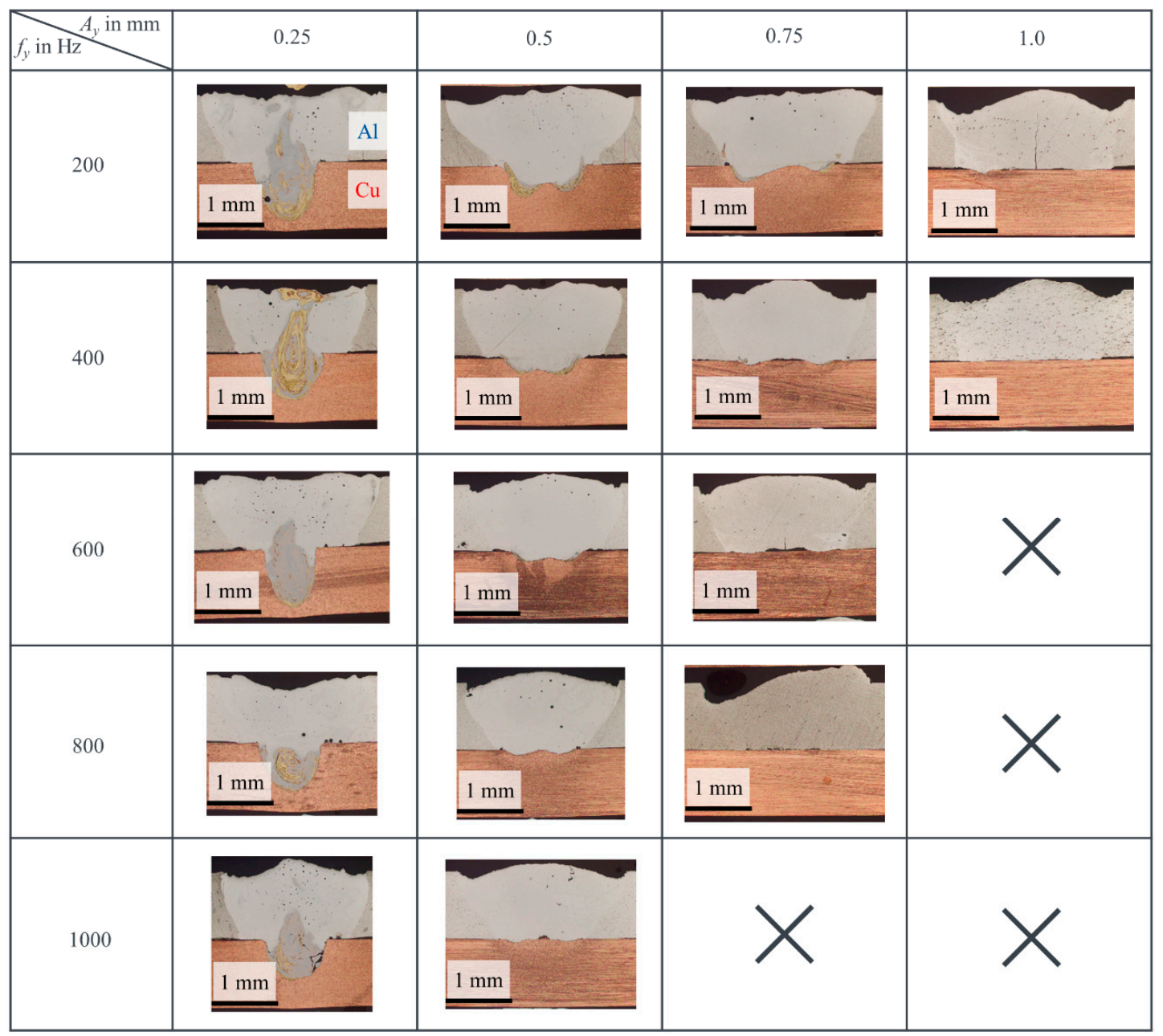

Figure 8. Micrographs of cross-sections from welds produced with spatial oscillation of the laser beam with $3.25 \mathrm{~kW}$ of laser power and a feed rate of $6 \mathrm{~m} / \mathrm{min}$.

At the smallest amplitude of $A_{y}=0.25 \mathrm{~mm}$ the weld seams resemble those obtained with conventional rectilinear welding. They exhibit a large welding depth into the lower $\mathrm{Cu}$ sheet and a strong mixing of the materials (indicated by the dark grayish and golden colored areas in the cross-sections). With increasing amplitude, the welding depth decreases and the seam width increases. At the same time the dark grayish and golden colored areas are significantly reduced. Cracks in the center of the weld in the $\mathrm{Al}$ sheet are visible in some of the welds produced with large lateral oscillation amplitudes. For large amplitudes and high frequencies, the laser power of $P=3.25 \mathrm{~kW}$ was not sufficient to achieve a penetration into the lower $\mathrm{Cu}$ sheet and a connection of the two sheets.

\subsection{Geometry of Weld Seams as a Function of Oscillation Parameters}

The welding depth into $\mathrm{Cu}$ is shown in Figure 9 as a function of the oscillation amplitude $A_{y}$ and frequency $f_{y}$. The measured welding depth decreases with both, increasing amplitude and increasing frequency, whereby the impact of the amplitude is stronger. Averaged over all measurements, $\partial d / \partial A_{y}$ is found to be $-0.2 \mathrm{~mm} / \mathrm{mm}$ and $\partial d / \partial f_{y}$ to be $-0.051 \mathrm{~mm} / 100 \mathrm{~Hz}$. The standard deviation is highest for the smallest oscillation amplitude, which indicates that the welding process is still instable and 
comparable to the rectilinear welding process without oscillation. This is in agreement with the highly fluctuating results of the rectilinear welds (compare also the cross-sections shown in Figure 8 for $A_{y}=0.25 \mathrm{~mm}$ and in Figure 6 for rectilinear welding). For higher oscillation amplitudes the standard deviations are very small, which indicates the stabilizing effect of the spatial oscillation of the laser beam on the geometry of the weld seam. Hence, the depth can be controlled coarsely with the oscillation amplitude and fine-tuned with the oscillation frequency.

Figure 10 shows the influence of oscillation amplitude and frequency on the seam width $w$ at the interface of the two sheets. The measured seam width increases with increasing amplitude as long as the locally available energy suffices to guarantee melting of the lower $\mathrm{Cu}$ sheet. This depends on the oscillation frequency. For small amplitudes the frequency has no effect on the resultant width of the weld seam. For amplitudes exceeding $0.5 \mathrm{~mm}$ the width is found to decrease.

Figure 11 shows the measured widths $w$ of the weld seams together with the respective welding depths $d$ into the $\mathrm{Cu}$ sheet. For processes without beam oscillation, the measurements are found to lie on one curve (red markers). This indicates that the width and depth cannot be set independently. The values for the processes with spatial beam oscillation are spread above the values of the processes without beam oscillation. Therefore, both geometrical features can be set independently and at same depth the generation of larger seam widths is possible in welding processes with beam oscillation.

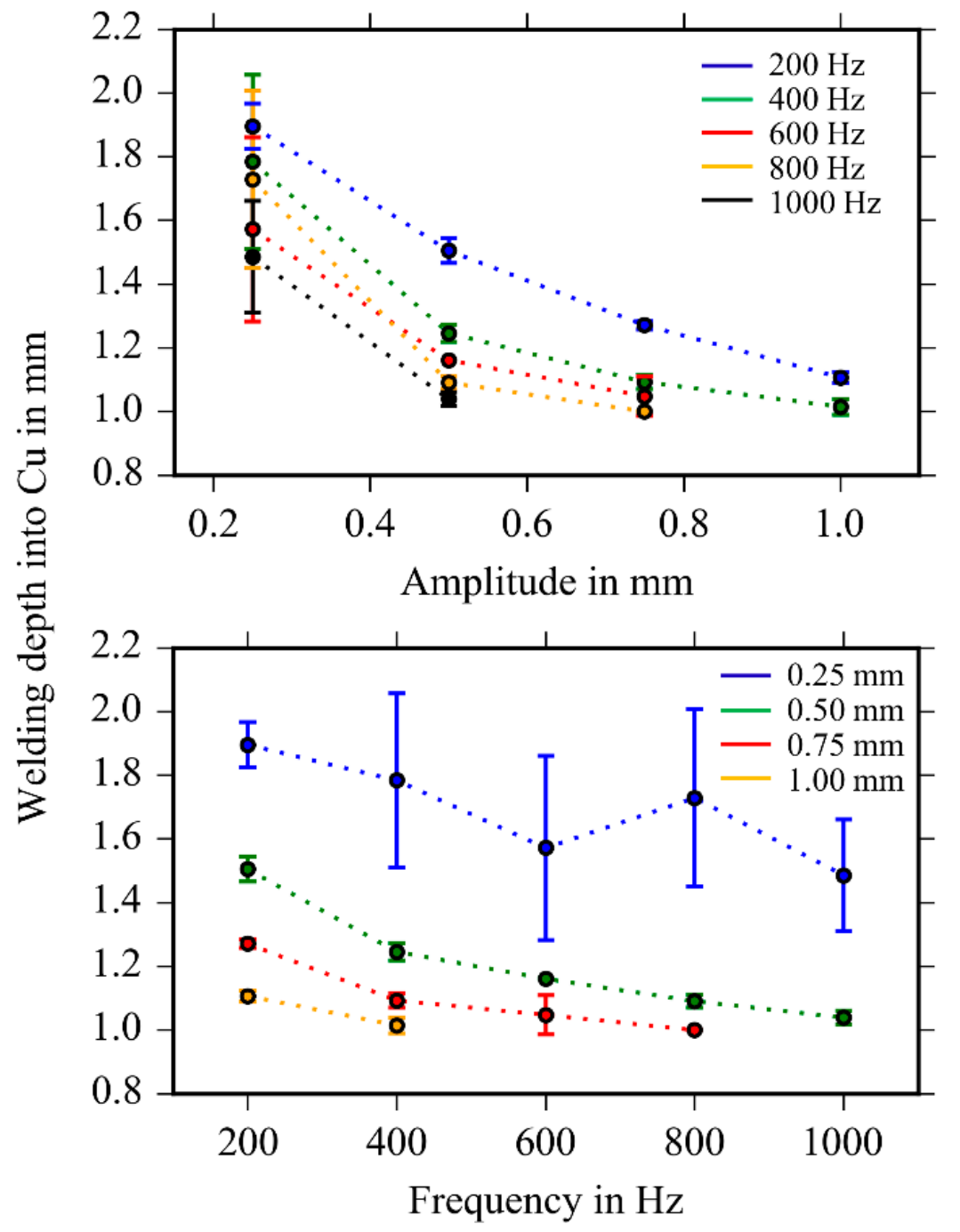

Figure 9. Welding depth into $\mathrm{Cu}$ in dependence on the oscillation frequency and amplitude. The error bars indicate the standard deviation. 


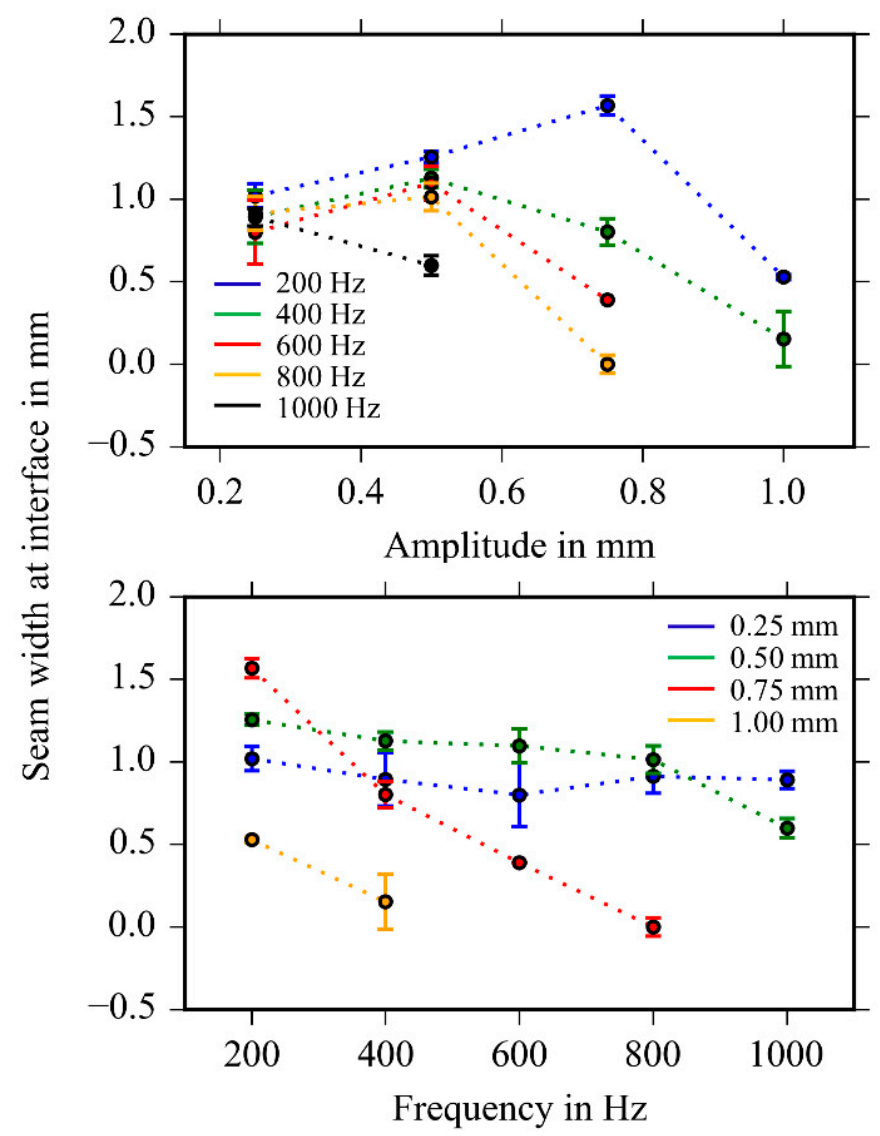

Figure 10. Seam width at the interface in dependence on the oscillation frequency and amplitude. The error bars indicate the standard deviation.

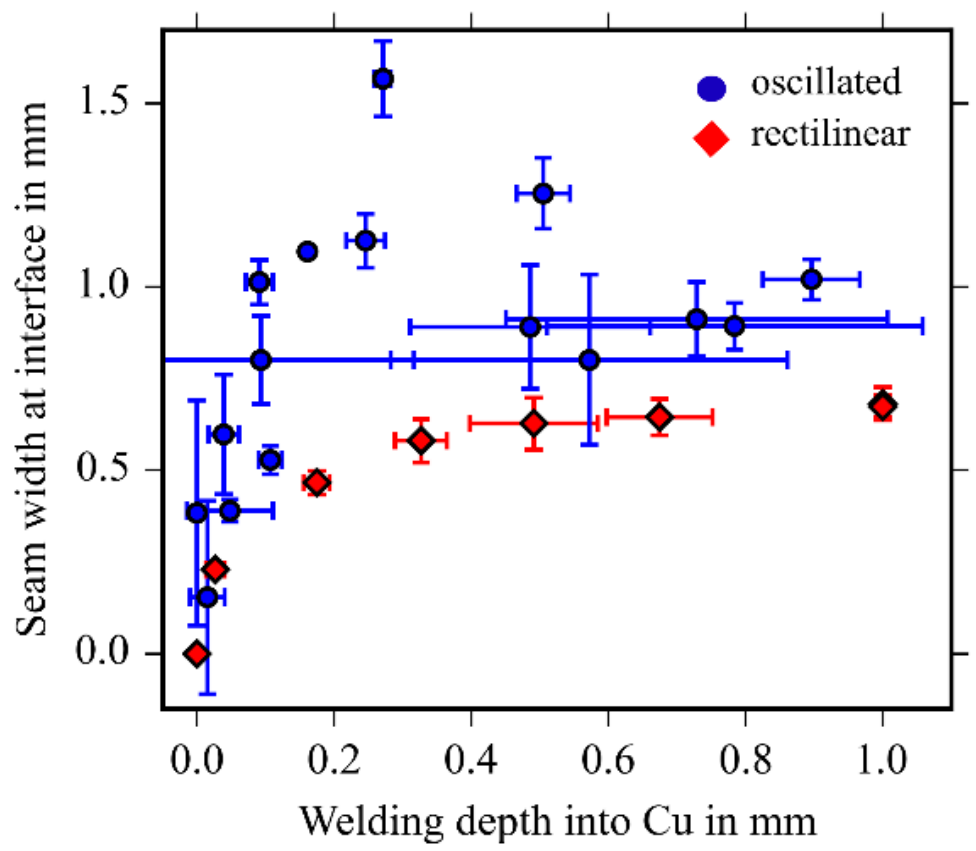

Figure 11. Seam width at interface over welding depth into $\mathrm{Cu}$ for welds produced with spatial beam oscillation (blue) and welding processes without beam oscillation (red). The error bars indicate the standard deviation. 


\subsection{Averaged Cu Content as a Function of the Geometry of the Weld Seams}

In laser beam welding, the liquid joining partners are mixed due to the strong convection in the weld pool. Therefore, the averaged $\mathrm{Cu}$ content in the weld seam is taken as a possible measure of the amount of mixed materials. Figure 12 shows the averaged $\mathrm{Cu}$ content in the weld seam in dependence on the welding depth $d$ into $\mathrm{Cu}(\mathrm{a})$ and seam width $w$ at the interface (b). It was found that the averaged $\mathrm{Cu}$ content is approximately proportional to the welding depth $d$ for both, the welding processes with and without spatial beam oscillation. A linear regression of the averaged $\mathrm{Cu}$ content on the welding depth into $\mathrm{Cu}$ (dotted lines in Figure 12a) yielded a coefficient of determination of $R^{2}=0.97$ for rectilinear welding and of $R^{2}=0.94$ in case of oscillated welding, respectively. This confirms the assumption stated before, that the amount of fused $\mathrm{Cu}$, and with this the averaged $\mathrm{Cu}$ content in the seam, is mainly influenced by the welding depth into the lower $\mathrm{Cu}$ sheet. The averaged $\mathrm{Cu}$ content increases rapidly with the width of the seam (because also the depth increases, see Figure 11). The increase is less steep for welds produced with beam oscillation. Again, the results for welding processes without beam oscillation are on one curve, whereas the results for welding processes with beam oscillation are spread. This further indicates that welding with spatial oscillation of the laser beam allows to independently set the geometrical features as well as the averaged $\mathrm{Cu}$ content of the generated weld seams, which is not possible with welding processes without beam oscillation.
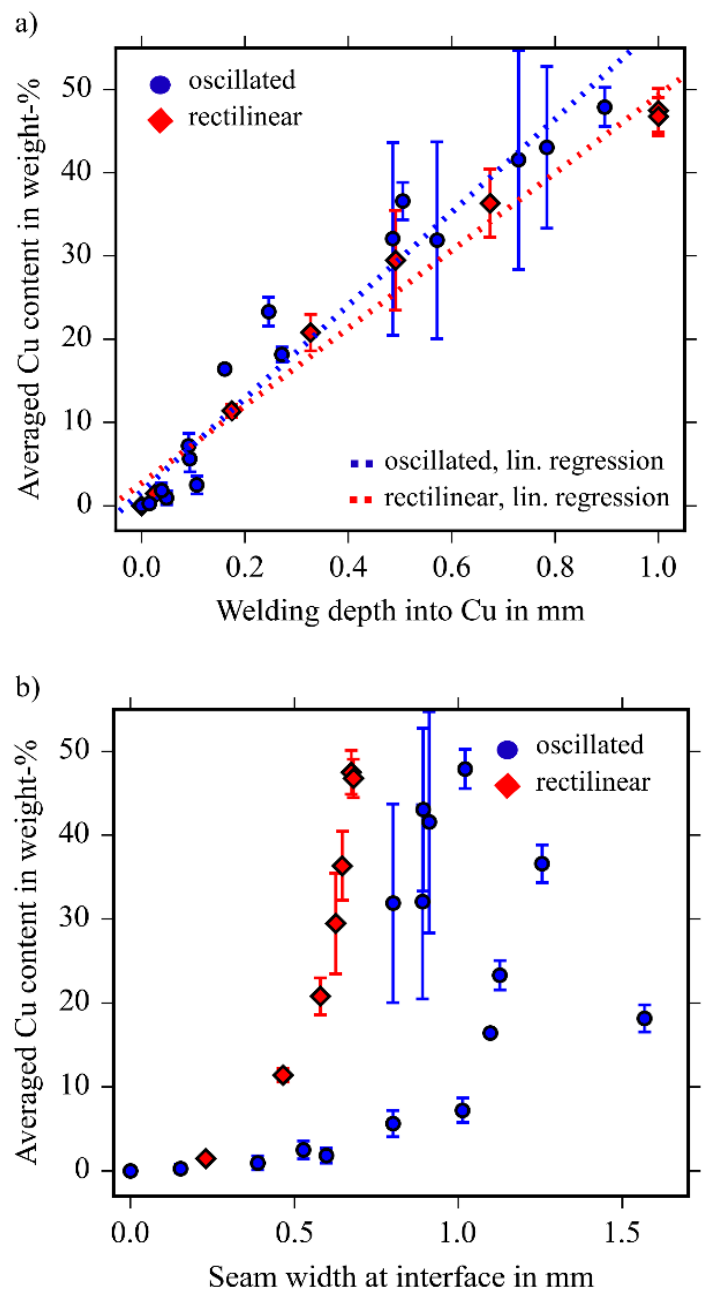

Figure 12. (a) Averaged Cu content in the weld seam in dependence on the welding depth. The markers indicate the measured values; the dotted lines represent a linear regression of the averaged $\mathrm{Cu}$ content on the welding depth; (b) averaged $\mathrm{Cu}$ content in the weld seam in dependence on the width of the seam. The error bars indicate the standard deviation. 
In Figure 13, the averaged $\mathrm{Cu}$ content in the weld seam is plotted together with the ratio of the seam width at the interface to the welding depth into $\mathrm{Cu}$ (width/depth-ratio). The averaged $\mathrm{Cu}$ content is found to decrease with an increasing width/depth-ratio. For the same share of copper in the seam, a higher width/depth-ratio can be achieved for the welds produced with beam oscillation, and higher width/depth-ratios can be achieved for welds produced with beam oscillation in general.

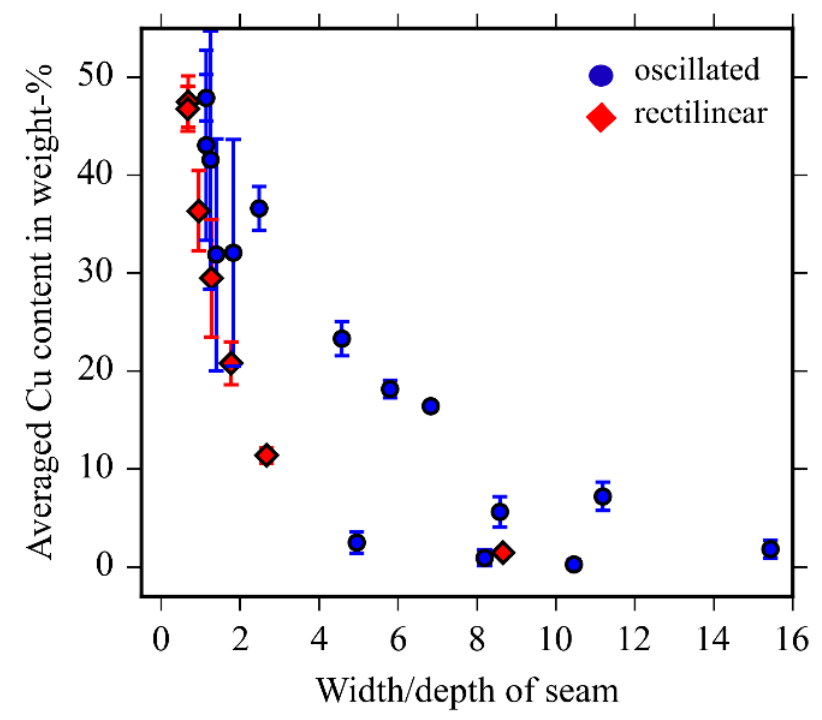

Figure 13. Dependence of the averaged $\mathrm{Cu}$ content in the weld seam on the ratio of seam width to depth for welds produced with spatial beam oscillation (blue) and rectilinear welds (red). The error bars indicate the standard deviation.

\subsection{Electrical Resistance as a Function of the Geometry of the Weld Seams}

Figure 14 shows the measured electrical resistances of the generated welds as a function of the welding depth into $\mathrm{Cu}(\mathrm{a})$ and the width/depth-ratio (b). The data measured for the welding processes with and without spatial beam oscillation are compared.

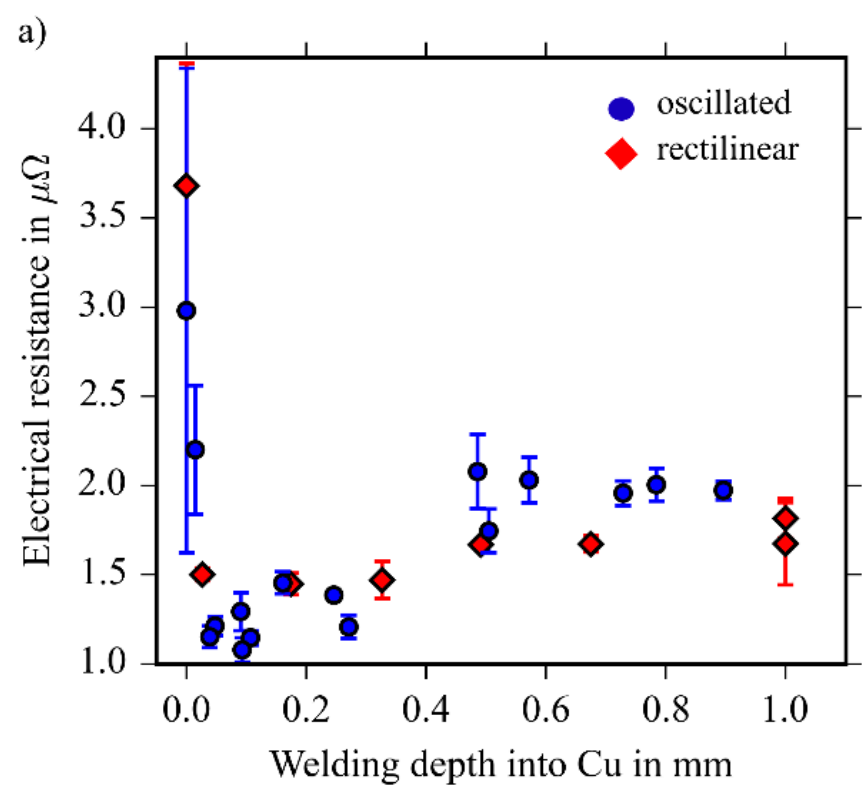

Figure 14. Cont. 


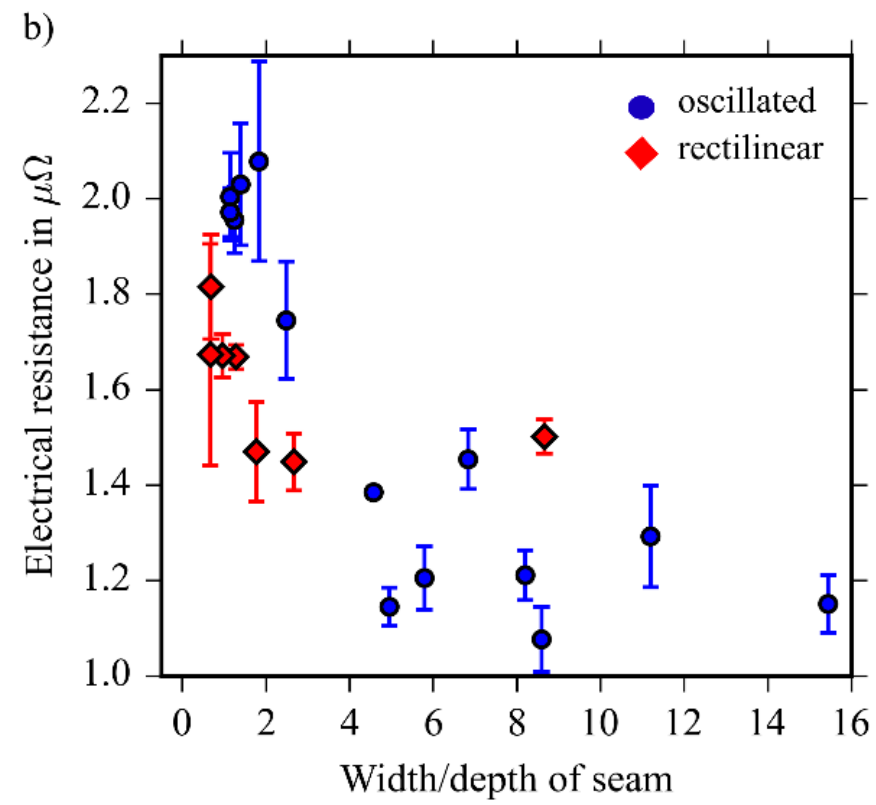

Figure 14. Electrical resistance in dependence on the welding depth into $\mathrm{Cu}(\mathrm{a})$ and on the ratio of weld seam width to depth (b).

It was found that a minimum welding depth into $\mathrm{Cu}$ is required to obtain reasonable resistance values. This minimum depth was found to be $0.02 \mathrm{~mm}$. If the welding depth in $\mathrm{Cu}$ is lower than this minimum required depth, the resistance increases $(>2 \mu \Omega)$ due to a lack of contact. The dependence of $\partial R / \partial(w / d)$ was found to be $-0.17 \mu \Omega$ for the welds produced with beam oscillation and $-0.025 \mu \Omega$ for the rectilinear welds. For low width/depth-ratios $(<3)$, the rectilinear welds result in lower (better) resistances. At higher width/depth-ratios $(>4)$, the welds produced with spatial beam oscillation exhibit lower electrical resistances than the rectilinear welds. With spatial beam oscillation the electrical resistance could be reduced by about $25 \%$ compared to the welding process without spatial beam oscillation. In general, higher width/depth-ratios and correspondingly lower electrical resistances can be achieved by welding with an oscillating beam. As a consequence, it was found that a high width to depth ratio is favorable to obtain low electrical resistance. This ratio is found to represent a reasonable measure for the suitability of the generated weld seams and it is proposed to merge the quality Factors (1) and (2) stated above.

\subsection{Correlation of Electrical Resistance and Mechanical Strength}

Shear tests were performed on the welded samples based on DIN EN ISO 14273 and the maximum shear strength was measured to quantify the mechanical quality of the generated junctions. These values were correlated with the measured electrical resistances. In Figure 15, both the maximum shearing loads together with the electrical resistances are plotted for the welds produced with and without spatial beam oscillation.

Maximum loads of up to $3 \mathrm{kN}$ were found which coincide with the lowest electrical resistance of $1.1 \mu \Omega$. The mechanical and electrical quality were found to correlate, thus for high shear strengths the lowest electrical resistances were measured and vice versa. It is therefore expected that process optimizations regarding one of these quality measures likewise optimize the other. Additionally, a measurement of the electrical resistance, which can be performed nondestructively, allows to predict the mechanical strength of the junction. These results are well consistent with correlations reported for welding of thin sheets with a single-mode laser [10]. 


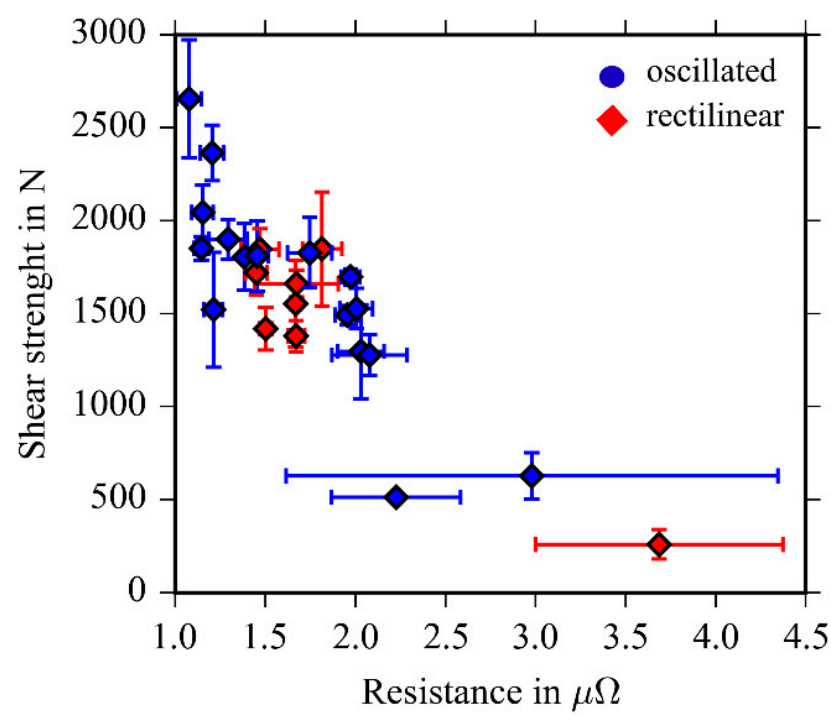

Figure 15. Correlation between electrical resistance and tensile strength for welds produced with (blue markers) and without (red markers) spatial beam oscillation.

\section{Discussion}

The presented investigations have shown that high width/depth-ratios are favorable together with a low and constant welding depth into the lower sheet. For the used material thickness of $1 \mathrm{~mm}$, this means that weld seam widths $>1 \mathrm{~mm}$ are required at welding depths of about $1 \mathrm{~mm}$. Since the high-reflective materials (for the laser wavelength of $1 \mu \mathrm{m}$ ) aluminum and copper are used for electrical applications, deep penetration welding is preferred to achieve high thermal efficiency. We conclude that spatial beam oscillation is a well suited method to achieve this. For a conventional rectilinear welding process, a respective large beam diameter of $>1 \mathrm{~mm}$ would be required. This in turn would lead to a higher required laser power since the threshold power for deep-penetration welding almost linearly scales with the beam diameter, as shown in Reference [15]. Moreover, at the transition from heat conduction welding to deep penetration welding, a step-like increase of the welding depth occurs, which is dependent on the size of the laser spot, as stated in Reference [16]. With increasing spot size this step also increases which makes it much more challenging to achieve low and constant welding depths in deep penetration welding for large beam diameters. In contrast, spatial oscillation of the laser beam allows to achieve lower and more stable welding depths in deep penetration welding mode compared to conventional rectilinear welding, as shown in Reference [6]. In addition, the use of two-axis scanners offers the possibility to adapt and optimize welding processes for different material and joint configurations, with the joining of battery taps for lithium-ion batteries being one possible application [1,2]. While the presented investigations quantified the influence of the processing parameters on the geometry and the resultant electrical and mechanical properties of the welds, the influence of the processing parameters on the amount and local distribution of intermetallic phases is subject to further research. Furthermore, a correlation between the electrical resistance and the tensile strength of the joints could be observed. The mechanical strength of the joints can therefore be estimated by measurements of the electrical resistance. This provides the possibility of a nondestructive method for testing the mechanical strength that is also faster and less expensive than conventional shear strength tests.

\section{Conclusions}

Laser beam welding of aluminum to copper with sheet thicknesses of $1 \mathrm{~mm}$ in overlap configuration was investigated using a high-power, multi-mode laser and spatial oscillation of the laser beam. The influence of the oscillation parameters amplitude and frequency on the geometrical 
features of the resultant weld seams were determined and the implications on the electrical resistance were examined. The averaged $\mathrm{Cu}$ content in the weld seam depended mainly on the welding depth into the lower $\mathrm{Cu}$ sheet. The welding depth into the lower $\mathrm{Cu}$ sheet decreased with both, increasing amplitude and increasing frequency, with the amplitude having a stronger influence, and the frequency allowing for a fine-tuning. Additionally, the spatial beam oscillation allowed to set the seam width at the interface and the welding depth into the lower $\mathrm{Cu}$ sheet virtually independent of each other, which was not possible with a rectilinear welding process. With this, high width/depth-ratios can be achieved even at low and constant welding depths into the lower $\mathrm{Cu}$ sheet. Low welding depths into the lower $\mathrm{Cu}$ sheet in combination with high width/depth-ratios $(>4)$ are favorable to obtain low electrical resistances, but a minimum welding depth $(>0.02 \mathrm{~mm})$ is required for a reasonable connection. These results confirm the influencing factors for a good weld stated at the beginning of the paper.

Author Contributions: Conceptualization, M.J. and F.F.; Methodology, M.J. and F.F.; Investigation, M.J. and F.F. Data Curation, M.J. and F.F.; Writing-Original Draft Preparation, M.J. and F.F; Writing-Review \& Editing, R.W. and T.G.; Supervision, R.W.; Project Administration, R.W.; Funding Acquisition, R.W. and T.G.

Funding: The presented work was funded by the Federal Ministry of Education and Research (BMBF) and experiments were performed in the context of the "ReMiLas" project. The responsibility for this paper is taken by the authors.

Acknowledgments: The RLW-A remote welding optics was provided by Scansonic MI GmbH and the laser source Laserline LDF 4000.8 was provided by Laserline GmbH, both within the scope of the project "ReMiLas".

Conflicts of Interest: The authors declare no conflict of interest.

\section{References}

1. Schmidt, P.A.; Schweier, M.; Zaeh, M.F. Joining of lithium-ion batteries using laser beam welding: Electrical losses of welded aluminum and copper joints. In Proceedings of the International Congress on Applications of Lasers and Electro-Optics (ICALEO 2012), Anaheim, CA, USA, 23-27 September 2012.

2. Kirchhoff, M. Laser applications in battery production-From cutting foils to welding the case. In Proceedings of the 2013 3rd International Electric Drives Production Conference (EDPC), Nuremberg, Germany, 29-30 October 2013; IEEE: New York, NY, USA, 2013; pp. 1-3.

3. Smith, S.; Blackburn, J.; Gittos, M.; Bono, P.D.; Hilton, P. Welding of dissimilar metallic materials using a scanned laser beam. In Proceedings of the 32nd International Congress on Applications of Lasers \& Electro-Optics (ICALEO), Miami, FL, USA, 6-10 October 2013; pp. 6-10.

4. Rabkin, D.M.; Ryabov, V.R.; Lozovskaya, A.V.; Dovzhenko, V.A. Preparation and properties of copper-aluminum intermetallic compounds. Powder Metall. Metal Ceram. 1970, 8, 695-700. [CrossRef]

5. Solchenbach, T.; Plapper, P. Mechanical characteristics of laser braze-welded aluminium-copper connections. Opt. Laser Technol. 2013, 54, 249-256. [CrossRef]

6. Sommer, M.; Weberpals, J.-P.; Müller, S.; Berger, P.; Graf, T. Advantages of laser beam oscillation for remote welding of aluminum closely above the deep-penetration welding threshold. J. Laser Appl. 2017, 29, 12001. [CrossRef]

7. Thiel, C.; Weber, R.; Johannsen, J.; Graf, T. Stabilization of a laser welding process against focal shift effects using beam manipulation. Phys. Procedia 2013, 41, 209-215. [CrossRef]

8. Kraetzsch, M.; Standfuss, J.; Klotzbach, A.; Kaspar, J.; Brenner, B.; Beyer, E. Laser beam welding with high-frequency beam oscillation. Welding of dissimilar materials with brilliant fiber lasers. Phys. Procedia 2011, 12, 142-149. [CrossRef]

9. Gedicke, J.; Olowinsky, A.; Artal, J.; Gillner, A. Influence of temporal and spatial laser power modulation on melt pool dynamics. In Proceedings of the 26th International Congress on Applications of Laser and Electro-Optics (ICALEO 2007), Orlando, FL, USA, 29 October-1 November 2007; pp. 816-822.

10. Solchenbach, T.; Plapper, P.; Wanye, C. Electrical performance of laser braze-weldedd aluminum-copper interconnects. J. Manuf. Processes 2014, 16, 183-189. [CrossRef]

11. Fetzer, F.; Jarwitz, M.; Stritt, P.; Weber, R.; Graf, T. Fine-tuned remote laser welding of aluminum to copper with local beam oscillation. Phys. Procedia 2016, 83, 455-462. [CrossRef] 
12. Heider, A.; Sollinger, J.; Abt, F.; Boley, M.; Weber, R.; Graf, T. High-speed X-ray analysis of spatter formation in laser welding of copper. Phys. Procedia 2013, 41, 112-118. [CrossRef]

13. Heider, A.; Stritt, P.; Hess, A.; Weber, R.; Graf, T. Process stabilization at welding copper by laser power modulation. Phys. Procedia 2011, 12, 81-87. [CrossRef]

14. Hagenlocher, C.; Fetzer, F.; Weber, R.; Graf, T. Benefits of very high feed rates for laser beam welding of AlMgSi aluminum alloys. J. Laser Appl. 2018, 30, 12015. [CrossRef]

15. Graf, T.; Berger, P.; Weber, R.; Hügel, H.; Heider, A.; Stritt, P. Analytical expressions for the threshold of deep-penetration laser welding. Laser Phys. Lett. 2015, 5, 56002. [CrossRef]

16. Hügel, H.; Graf, T. Laser in der Fertigung; Vieweg + Teubner, GWV Fachverlage GmbH: Wiesbaden, Germany, 2009.

2018 by the authors. Licensee MDPI, Basel, Switzerland. This article is an open access article distributed under the terms and conditions of the Creative Commons Attribution (CC BY) license (http://creativecommons.org/licenses/by/4.0/). 